\title{
The in vitro influences of neurotensin on the motility characteristics of human U373 glioblastoma cells
}

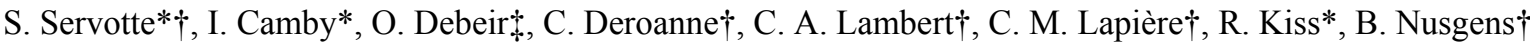 \\ and C. Decaestecker* \\ *Laboratory of Toxicology, Institute of Pharmacy, Université Libre de Bruxelles, Brussels, $\dagger$ Laboratory of Connective Tissue Biology, \\ Université de Liège, Liège, $\$$ Department of Logical and Numerical Systems, Faculty of Applied Science, Université Libre de Bruxelles, \\ Brussels, Belgium
}

\begin{abstract}
Astrocytic tumours are associated with dismal prognoses due to their pronounced ability to diffusely invade the brain parenchyma. Various neuropeptides, including gastrin, are able to modulate tumour astrocyte migration. While neurotensin has been shown to influence the proliferation of glioma cells and the migratory ability of a large set of other cell types, its role in glioma cell migration has never been investigated. Neurotensin-induced modifications to the motility features of human U373 glioblastoma cells therefore constitute the topic of the present study. We evidenced that three subtypes of neurotensin receptors (NTR1, NTR2 and NTR3) are expressed in U373 glioblastoma cells, at least as far as their mRNAs are concerned. Treating U373 tumour cells with $10 \mathrm{nM}$ neurotensin markedly modified the morphological patterns of these cells and also profoundly altered the organization of their actin cytoskeletons. Pull-down assays revealed that neurotensin induced the activation in U373 cells of both Racl and Cdc42 but not RhoA. Scratch wound assays evidenced that neurotensin $(0.1$ and $10 \mathrm{nM})$ very significantly inhibited wound colonization by U373 cells cultured in the absence of serum. In addition, quantitative phase-contrast videomicroscopy analyses showed that neurotensin decreases the motility levels of U373 glioblastoma cells when these cells are cultured on plastic. In sharp contrast, neurotensin stimulates the motility of U373 cells when they are cultured on laminin, which is a pro-adhesive extracellular matrix component ubiquitously secreted by glioma cells. Our data thus strongly suggest that, in addition to gastrin, neurotensin is a neuropeptide capable of modulating tumour astrocyte migration into the brain parenchyma.
\end{abstract}

Keywords: cell migration, glioblastoma, neurotensin, Rho GTPases, scratch wound, videomicroscopy

\section{Introduction}

The World Health Organization (WHO) classifies astrocytic tumours into four histopathological grades according to their levels of malignancy [1]. Grade I includes benign tumours like pilocytic astrocytomas and subependymal giant cell astrocytomas, Grade II tumours are associated with a rather good prognosis of 10-20 years' survival after the initial diagnosis while Grades III (anaplastic astrocytomas) and IV (glioblastomas) are highly malignant tumours associated with dismal prognoses [2]. Indeed, about $90 \%$ of glioblastoma patients die in the year following the initial diagnosis of their tumours. The malignant nature of astrocytic tumours is directly related to their ability to diffusely invade the brain parenchyma, so making complete surgical resections impossible [2]. Various neuropeptides (for example, angiotensin, bombesin, bradykinin, cholecystokinin, endothelin, gastrin and neurotensin, etc.) are able to modify the biological behaviour of tumour astrocytes [3]. We accordingly show that chole-cystokinin/gastrin-related peptides modify both the cell proliferation [4,5] and the migratory [6-8] characteristics of glioblastoma cells. Astrocytic tumours also express neurotensin receptors (NTRs) [9], and we have previously shown that neurotensin is able to significantly modify the proliferation rates of various human astrocytic tumour cell lines [10].

The invasive abilities of individual tumour astrocytes mainly depend on their migratory potential, which is related to three processes, that is, their adhesion to extracellular matrix (ECM) components and other cells, their motility involving the dynamics of the cell cytoskeleton, and their invasive ability that requires the degradation of matrix proteins by proteolytic enzymes. To migrate, glioma cells secrete ECM components that facilitate their motility [11-13]. Laminin - a pro-adhesive ECM component - is ubiquitously secreted by glioma cells $[11,12,14]$; it is upregulated in human high-grade diffuse astrocytic tumours [12,14] and strongly stimulates glioma cell motility in vitro [15]. The major steps involved in cell movement are the extension of a leading edge protrusion or lamellipodium, the establishment of new adhesion sites at the leading edge, the contraction of the cell body and the release of the adhesion at the rear [16]. All these steps involve the assembly, the disassembly or reorganization of the actin cytoskeleton. Most neuropeptides, including neurotensin, function biologically through binding to specific G-protein-coupled receptors (GPCRs) on the surface of the target cells [17], and this 
binding to GPCRs in turn induces profound modifications in the organization of the actin cytoskeleton [18]. Small GTPases of the Rho family (that is, the Rho-GTPases), including RhoA, Cdc42 and Rac1, play a pivotal role in regulating the signalling pathways which are activated by the binding of neuropeptides to GPCRs [18] and which are relevant to cell migration [16]. These GTPases act as molecular switches to control the signal transduction pathways by cycling between a GDP-bound inactive form and a GTP-bound active one [16]. In their GTP-bound state, they interact with downstream targets (effectors) to elicit a variety of intracellular responses, including the reorganization of the actin cytoskeleton. While RhoA regulates the assembly of contractile acto-myosin filaments, Racl and $\mathrm{Cdc} 42$ regulate the polymerization of actin to form peripheral lamellipodial and filopodial protrusions respectively [19]. In addition, these three GTPases promote the assembly of integrin-based matrix adhesion complexes [20-22].

The aim of the present work is to characterize the effects of neurotensin on the motility characteristics of the U3 73 model, an aggressive human glioma of astrocytic origins [23-25]. Neurotensin is widely distributed in the central nervous system (CNS) and its peripheral tissue, and its actions are mediated by specific receptors. Of the three subtypes of NTRs cloned, NTR1 and NTR2 belong to the family of GPCRs while NTR3 is a new type of neuropeptide receptor in the form of a $95-\mathrm{kDa}$ protein (identical to gp95/sortilin) with a single transmembrane domain [9,26-28]. Different studies of rat CNS have revealed a widespread expression of these NTRs throughout the adult brain [29-31]. We made use of anRT-PCR approach to characterize at mRNA level the type of NTR present in U373 glioblastoma cells. In addition, we investigated the influence of neurotensin on the levels of activity of RhoA, Cdc42 and Racl, and on the organization of the actin cytoskeleton. Finally, we made use of two distinct cell migration assays to characterize the influence of neurotensin on the motility features of U373 cells cultured on plastic and laminin.

\section{Materials and methods}

\section{Cell culture}

The human glioma cell line U373, whose unique astrocytic origin we had previously confirmed [23,24], was obtained from the American Type Culture Collection (ATCC, Manassas, VA, USA; HTB14). The cells were maintained as monolayers in a specific medium, as detailed elsewhere [4,24].

\section{Compounds}

Neurotensin and laminin (from the basement membrane of Engelbreth-Holm-Swarm murine sarcoma) were purchased from Sigma (St Louis, MO, USA). Culture dishes were coated with laminin by allowing a stock solution $(0.833 \mathrm{ng} / \mathrm{ml})$ to dry on the surface for one night at room temperature. The dishes were rinsed twice with sterile phosphate-buffered saline (PBS, GibcoBRL, InvitrogenSA, Merelbeke, Belgium) just before the plating of the cells.

\section{Analysis of NTRs mRNA expression}

The U373 tumour cells were grown to subconfluence in plastic Falcon dishes, and total RNA was prepared with the High Pure RNA Isolation Kit (Roche Diagnostics, Vilvoorde, Belgium) according to the manufacturer's recommendations. The quantities of RNA extracted were measured with the Ribogreen Kit (Molecular Probes, Eugene, OR, USA). A second quantification was carried out by means of a spectrophotometer (at 260 and 280 $\mathrm{nm}$ ), which also enabled the sample quality to be checked (by means of the 260/280 ratio). Ten nanograms of total RNA were reverse-transcribed and amplified using the GeneAmp Thermostable rTth Reverse Transcriptase RNA PCR Kit (Perkin-Elmer, Boston, MA, USA) and specific pairs of primers (InvitrogenSA). The sequence of the primers, the numbers of PCR cycles and the size of the RT-PCR products are described in Table 1. These products were analysed on $10 \%$ polyacrylamide gels. After staining with GelStar dye (FMC BioProducts, Rockland, ME, USA) the signals were quantified using Fluor-S Multilmager (Bio-Rad, Hercules, CA, USA). The amplification of the 28S rRNA was carried out to check each RNA sample analysed (data not shown). The analysis of the mRNA expression or each NTR included a negative control (that is, water) which evidenced no band (data not shown).

\section{Pull-down assays}

Active GTP-bound forms of the three Rho GTPases were measured on U373 cells cultured on plastic as described by Ren et al. [32] and Sander et al. [33]. Cells were chilled on ice and lysed in an ice-cold buffer (50 $\mathrm{mM}$ Tris $\mathrm{pH} 7.2$ containing $1 \%$ Triton X-100, $150 \mathrm{mM} \mathrm{NaCl}, 10 \mathrm{mM} \mathrm{MgCl}, 10 \mu \mathrm{g} / \mathrm{ml}$ each of leupeptin and 
aprotinin, and $0.1 \mathrm{mM}$ PMSF). The cell lysates were clarified by centrifugation at $13000 \mathrm{~g}$ at $4^{\circ} \mathrm{C}$ for $8 \mathrm{~min}$. Aliquots of the supernatants were denatured in SDS-PAGE lysis buffer $(\mathrm{v} / \mathrm{v})$ in order to measure the total amount of the Rho GTPases by Western blotting. For the pull-down assays the supernatants were incubated at $4^{\circ} \mathrm{C}$ for $30 \mathrm{~min}$ with $30 \mu \mathrm{g}$ of a fusion protein between glutathione-S-transferase (GST) and either the PBD domain of the Rac1- and Cdc42-effector PAK, or the RBD domain of the RhoA-effector Rhotekin, linked to glutathione-Sepharose beads (Amersham Biosciences, Buckinghamshire, UK). The beads were washed four times in lysis buffer and denaturated in SDS-PAGE buffer. The total and activated proteins were analysed in parallel by Western blotting with mouse monoclonal antibodies against RhoA, Racl or Cdc42. The anti-RhoA antibody (1/400) was purchased from Santa Cruz Biotechnology (Santa Cruz, CA, USA), the anti-Racl (1/1000) from Upstate Biotechnology (Lake Placid, NY, USA), and the anti-Cdc42 (1/250) from Transduction Laboratories (San Diego, CA, USA).

\section{Analysis of the actin cytoskeleton}

Fluorescent phallacidin conjugated with Alexa Fluor ${ }^{\circledR} 488$ fluorochrome (Molecular Probes Inc., Eugene, OR, USA) was used to label the fibrillar actin, and Alexa Fluor ${ }^{\circledR}$ 594-conjugated DNAseI (Molecular Probes Inc.) to stain the globular actin. The cells were cultured $48 \mathrm{~h}$ on glass coverslips prior to the fluorescence staining, as described elsewhere [8].

\section{Cell motility measurements by means of computer-assisted videomicroscopy}

We developed and implemented a specialized software package on computers connected to phase-contrast videomicroscopy systems placed in $37^{\circ} \mathrm{C}$-heated incubators [6,34]. This package enables the trajectories of individual cells to be established and quantitatively analysed (Figure $1 \mathrm{~A}, \mathrm{~B}$ ) . The cell-tracking algorithm is based on a model-based approach using an adapted mean-shift process which enables each cell to be tracked efficiently for hours and which is able to produce detailed descriptions of individual cell trajectories [34]. We validated this software on several cell culture experiments by means of comparisons with human-controlled analyses [34]. The images were acquired and stored as previously described [6], Briefly, they were obtained under a phase-contrast microscope (Olympus, Aartselaan, Belgium; model 1X50, with a 10:1 magnification ratio) with a CCD video camera (Hitachi Denshi, Tokyo, Japan; model KP-M1E/K-S10) coupled to an acquisition board (32-bits Matrix Vision PC-GRAB-GI frame grabber). Image acquisition was effected every $4 \mathrm{~min}$ over a number of hours (typically $24 \mathrm{~h}$, that is, 360 images). The dimensions of the images were $700 \times 500$ pixels discretized into 256 grey levels ( 8 bits per pixel). The parameter used to characterize each cell trajectory was the Maximum Relative Distance from the point of Origin (MRDO). This refers to the greatest linear distance between the original position of a cell (at time $=0$ ) and the farthest position reached by the cell in its trajectory (Figure 1C). The MRDO is this maximum distance normalized by the observation time for the cell analysed (to be able to compare cell trajectories corresponding to different observation times). The neurotensin effects were evaluated in terms of the MRDO variable on particular and complete cell populations. This is illustrated in Figure 1D, which shows how to identify a subpopulation of cells consisting of the $25 \%$ most motile ones (see the hatched vertical line) on the basis of the distribution of the MRDO values (the black bars).

Table 1: Primers used to evidence the mRNA expression of NTRs

\begin{tabular}{llcc}
\hline & Oligonucleotide sequence (5'to 3') & Number of cycles & Size of PCR products \\
\hline NTR1 sense & GCTTAAGAAGGTCGCCTAAGCCTA & 40 & $423 \mathrm{bp}$ \\
NTR1 antisense & GTTTGGCAGGAAGTGCAGCGAATA & \\
NTR2 sense CACTACTTCTACATGGTGACCAACA & 40 & $474 \mathrm{bp}$ \\
NTR2 antisense CTAAGCACTTTAGTCTCAGGCAACA & \\
NTR3 sense CGTGTGTCAGAATGGTCGAGACTA & 40 & $539 \mathrm{bp}$ \\
NTR3 antisense GGTCCTCATCTGAGTCATCATGATA & \\
\hline
\end{tabular}

NTR, neurotensin receptor; bp, base pairs. 
Figure 1: Cell motility tracking by means of computer-assisted videomicroscopy Starting from the initial cell positions indicated by the user (A), the method is able to reconstitute individual cell trajectories over dozens of hours (B). The level of individual cell motility is measured by means of the MRDO (Maximum Relative Distance from the point of Origin) variable, which is the maximum distance covered by a cell (red line in panel C) normalized by the observation time for this cell. Panel D illustrates both the distribution (in percentage) of the MRDO values computed on a cell population and the identification of the subpopulation consisting of the $25 \%$ most motile cells (characterized by the $25 \%$ highest MRDO values, see the vertical hatched line).
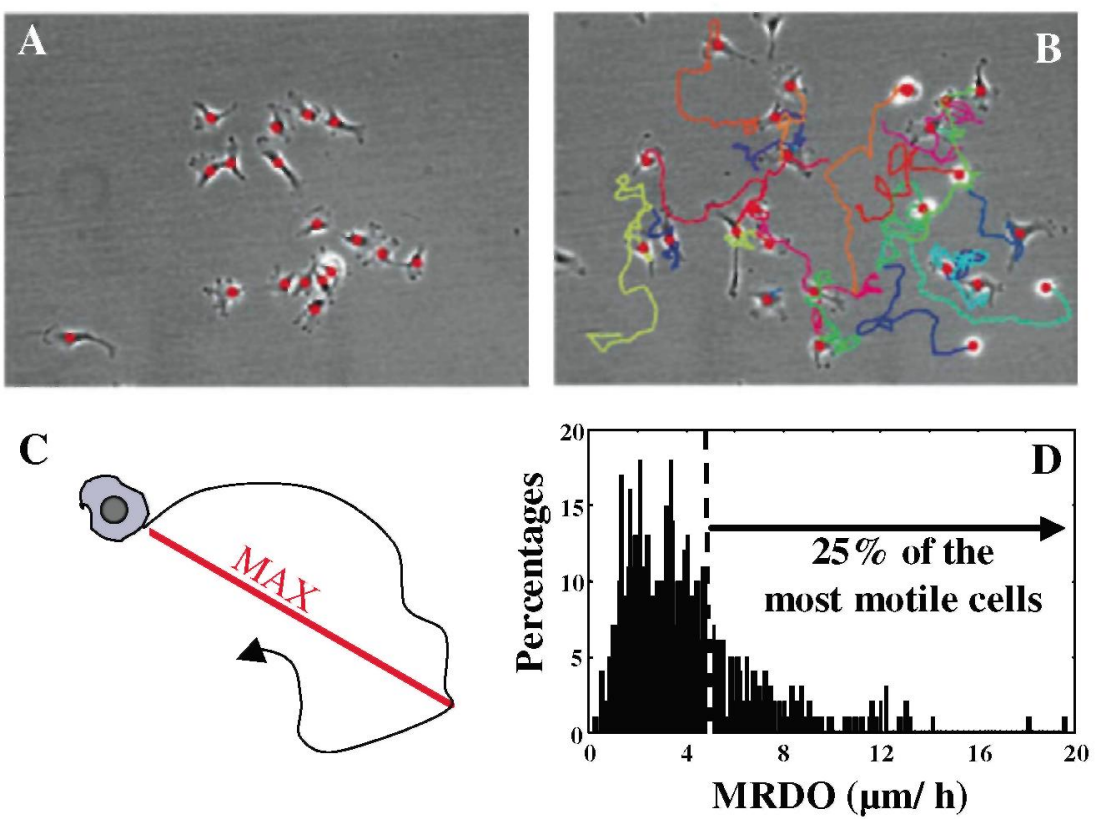

\section{Scratch wound assay}

The U3 73 glioblastoma cells were grown to confluence in six well dishes. Scratch wounds were made by creating a linear decellularized region using a pipette tip (as illustrated in the Results). The cells were washed twice with PBS before their incubation in culture medium with neurotensin $(0.1,10$ and $1000 \mathrm{nM})$. The colonization of the wound by the TJ3 73 cells cultured in a serum-free medium or in a medium supplemented with $5 \%$ foetal bovine serum and in the presence or the absence (control) of neurotensin was analysed for $40 \mathrm{~h}$ (at different points of time). Six fields of each of the three wounds analysed per condition were photographed 0 , 15,24 and $40 \mathrm{~h}$ after the neurotensin treatment. An algorithm developed in our laboratory was used on the basis of these digital frames to quantify the area progressively filled by the cells over the period of the experiment.

\section{Statistical analysis}

Because the conditions for applying the parametric tests were not satisfied, we used nonparametric tests to compare independent groups of numerical data. Statistical comparisons between the multiple groups of cells were made by first carrying out the Kruskal-Wallis test (a non-parametric one-way analysis of variance). In cases where this test revealed significant differences, we investigated by means of the Mann-Whitney test whether any of the groups of treated cells differed from control.

\section{Results}

NTR1, NTR2 and NTR3 mRNAs are expressed in human U373 glioblastoma cells

Figure 2 shows that the mRNAs for the three receptors identified to date for neurotensin are present in human U373 glioblastoma cells, that is, NTR1 (lane B), NTR2 (lane C) and NTR3 (lane D). In contrast, we did not evidence any secretion of neurotensin by these cells (by means of an Elisa assay, data not shown).

Neurotensin activates small GTPases in human U373 glioblastoma cells cultured on plastic and modifies their morphology and actin cytoskeleton organization

Figure 3A,B show morphological illustrations of U373 tumour cells cultured on plastic in the absence or the presence of $10 \mathrm{nM}$ neurotensin. These illustrations show that neurotensin induced morphological responses by 
increasing the number of filopodial protrusions ending in adhesion plaques in the treated cells (see the arrow in Figure 3B). As illustrated in Figure 3C,D, the staining of the fibrillar and globular actin revealed that the neurotensin increased the overall amount of fibrillary (green fluorescent) actin and induced its accumulation at the tips of the protrusions (see arrows in Figure 3D). The activity of the Rho GTPases, RhoA, Rac1 and Cdc42, was measured by means of pull-down assays. The U3 73 cells were either treated with $10 \mathrm{nM}$ neurotensin for 5 or $10 \mathrm{~min}$, or left untreated (control). The cells treated for $5 \mathrm{~min}$ with the culture medium supplemented with serum $(5 \%)$ were taken as positive control for Racl activation [35]. Figure $3 \mathrm{E}$ shows that while neurotensin did not activate RhoA, it did activate Racl and Cdc42 in a time-dependent manner in the U373 tumour cells. The total levels of the Rho GTPases were not altered by the neurotensin treatment. These neurotensin-induced effects on the GTPases activity can at least partly explain the morphological and the cytoskeletal changes seen in the neurotensin-treated U373 tumour cells.

Figure 2: $m R N A$ expression of the neurotensin receptors in U373 cells. Lane A shows the DNA ladder, lane B the NTR1 PCR product (423 bp), lane C the NTR2 PCR product (474 bp), lane D the NTR3 PCR product (its size should be at 539 bp but appears at more than 500 bp).

A B $\quad$ C $\quad$ D

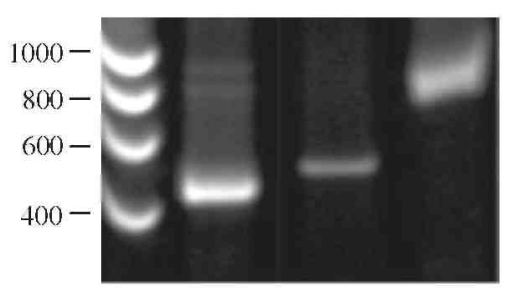

Figure 3: Neurotensin-mediated effects on cell morphology and cytoskeleton and Rho-GTPase activation. Panels $A$ and B illustrate the morphological aspects observed under phase-contrast microscopy of the D373 cells (cultured on plastic) left untreated or treated with neurotensin $\left(10^{-8} M\right)$ respectively. The treated cells exhibited an increased number of filopodial protrusions ending in adhesion plaques (see the arrow in panel B). Panels $C$ and D illustrate the modifications to the actin cytoskeleton (F-actin labelled in green and $G$-actin in red) observed in the D373 cells treated with neurotensin $\left(10^{-8} M, D\right)$ as compared with the untreated cells (C). Panel E shows the results of the Rho GTPase activation assay carried out on the D3 73 cells cultured without any serum (a), treated for 5 min with a medium containing 5\% serum (b), and with neurotensin at $10^{-8} \mathrm{M}$ for 5 (c) and 10 (d) $\mathrm{min}$.
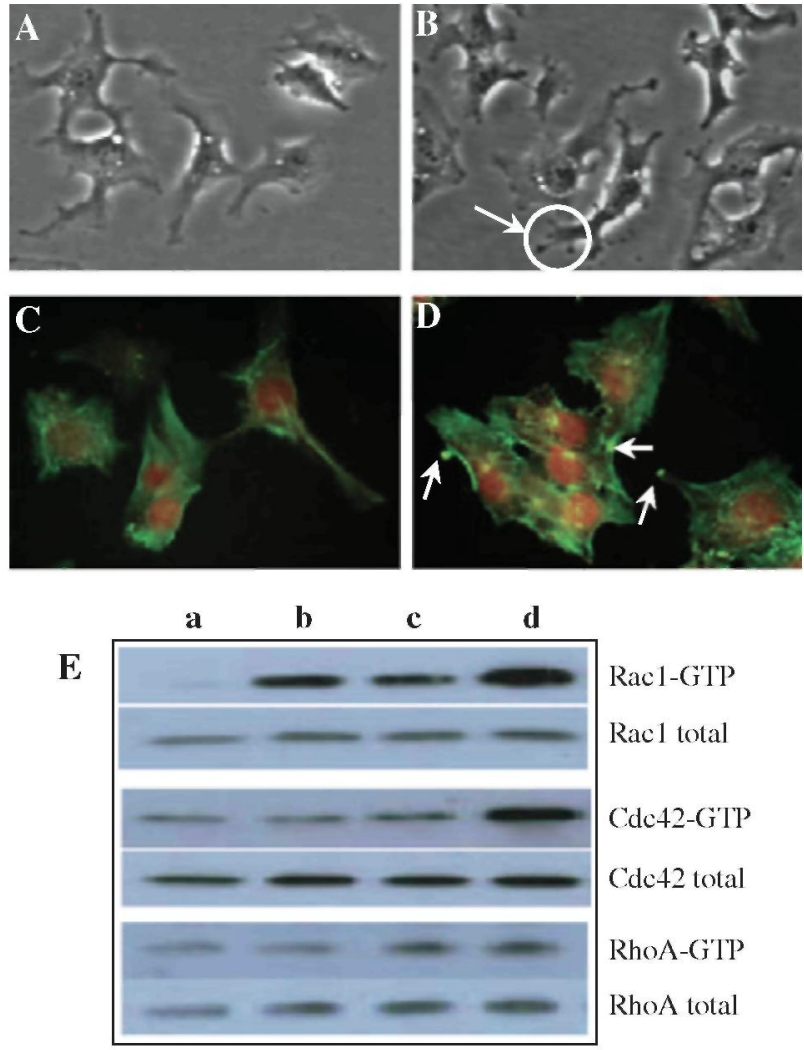


\section{Neurotensin decreases the motility of U373 glioblastoma cells cultured on plastic in a serum-free medium}

We used an in vitro wound-healing assay to determine the effect of neurotensin on U373 cell motility. Cell-free zones were created in confluent U373 monolayers by scratching off cells with a pipette tip. Each cell-free zone (see the black rectangle in Figure 4A) was approximately 250-300 $\mu \mathrm{m}$ wide and several millimetres long. Timelapse microscopy was used to analyse the recolonization rate of the cell-free zone (Figure 4B). Whereas neurotensin had no effect on U373 tumour cell motility when these cells were cultured in the presence of $5 \%$ foetal bovine serum (Figure 4C), it significantly reduced the motility level at 0.1 and $10 \mathrm{nM}(P<0.001$ at $40 \mathrm{~h}$ post treatment) when the cells were cultured in a serum-free medium (Figure 4D). At $1 \mu \mathrm{M}$ the neurotensininduced decrease in U3 73 tumour cell motility was much less accentuated $(P<0.05$ at $40 \mathrm{~h}$ post treatment; Figure 4D).

Neurotensin decreases the motility of U373 glioblastoma cells cultured on plastic, but increases it when U373 cells are cultured on laminin

Computer-assisted phase-contrast microscopy (quantitative videomicroscopy) enabled the neurotensin-induced effects on the motility levels of the U373 glioblastoma cells to be quantitatively determined. These motility levels refer to the largest linear distance travelled by individual U3 73 cells per hour, and were obtained by computing the MRDO variable expressed in $\mu \mathrm{m} / \mathrm{h}$. Figure $5 \mathrm{~A}$ shows that 0.1 and $10 \mathrm{nM}$ neurotensin significantly decreased the levels of motility of the whole U373 cell population analysed ('100\%') as well as of the $25 \%$ most motile U373 cells (determined as shown in Figure 1D) when the cells were cultured on plastic. In sharp contrast, neurotensin increased the levels of motility of U373 glioblastoma cells cultured on laminin, with a more pronounced effect on the $25 \%$ most motile cells than on the U373 cell population as a whole (Figure 5B). Higher doses (that is, $1 \mu \mathrm{M}$ or higher) of neurotensin were not assayed in this cell motility assay because the woundhealing experiment had previously shown that pharmacological doses of neurotensin are no more effective on U373 cell motility (Figure 4).

Figure 4: Neurotensin-mediated effects on scratch wound colonization by D373 cells. Illustration of (A) a scratch wound carried out by means of a pipette tip and (B) recolonized over 40 h by U373 cells cultured in a medium supplemented with $5 \%$ foetal bovine serum. The percentages of surface area filled by the cells are quantified in the black rectangles shown in panels $A$ and $B$ and in function of the time line depicted on the $x$ axes of panels $C$ and $D$. These panels show the recolonization curves measured in the case of the cells cultured in a medium supplemented with 5\% foetal bovine serum (C), and in the absence of serum (D). The data (expressed in percentage $)$ are displayed as the means $\pm S E(* P \leq 0.05, * * P \leq 0.01, * * * P \leq 0.001)$. Black squares $=$ control; open squares $=$ neurotensin at $10^{-10} \mathrm{M}$; open circles = neurotensin at $10^{-8} \mathrm{M}$; open triangles $=$ neurotensin at $10^{-6} \mathrm{M}$.
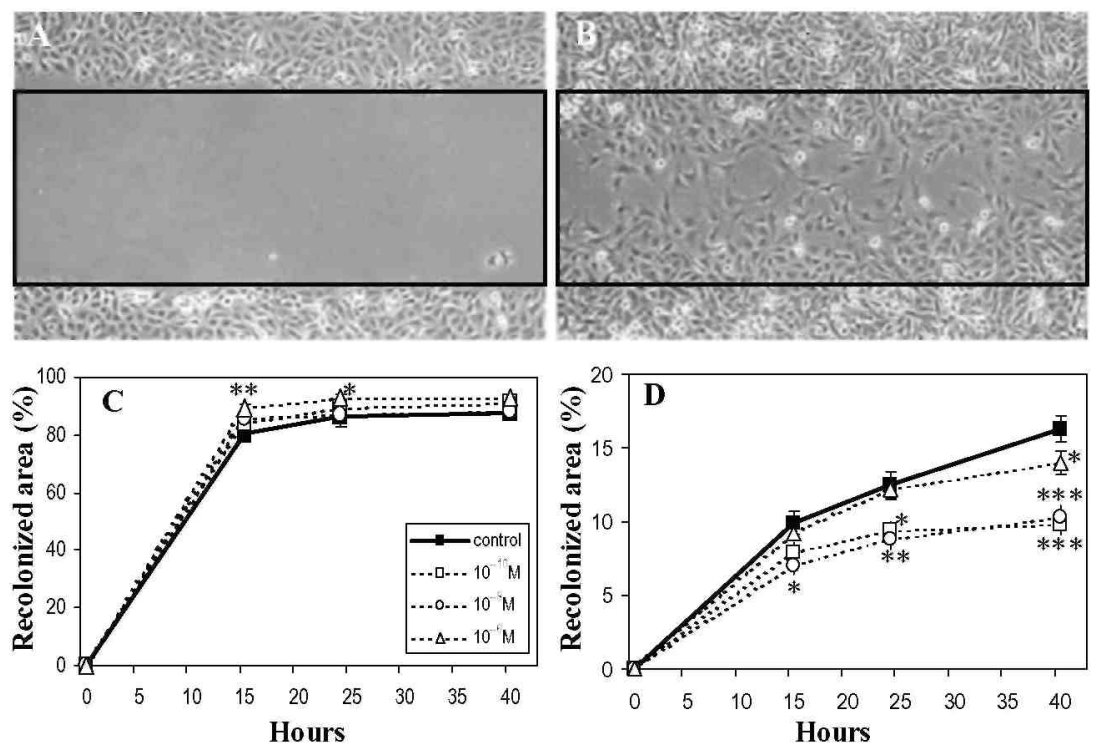
Figure 5: Neurotensin-mediated effects on the motility of the U373 cells quantified by means of computerassisted videomicroscopy Panels $A$ and $B$ show the variation (\%) of the MRDO (Maximum Relative Distance from the point of Origin) values induced by neurotensin in the case of U373 cells grown on a plastic (A) or a laminin-coated support (B). The MRDO mean of untreated cells is arbitrarily set at $0 \%$. The results are pooled from at least three independent experiments over a tracking period of $12 \mathrm{~h}$ and are shown relative to both the whole cell population analysed (100\%) and to the $25 \%$ most motile one (determined as shown in Figure $1 D$ ). The variations induced by neurotensin at $10^{-10}$ and $10^{-8}$ M are expressed in terms of the means $\pm S E$ (ns, not significant; $* P<0.05, * * P<0.01, * * * P<0.001$ ).

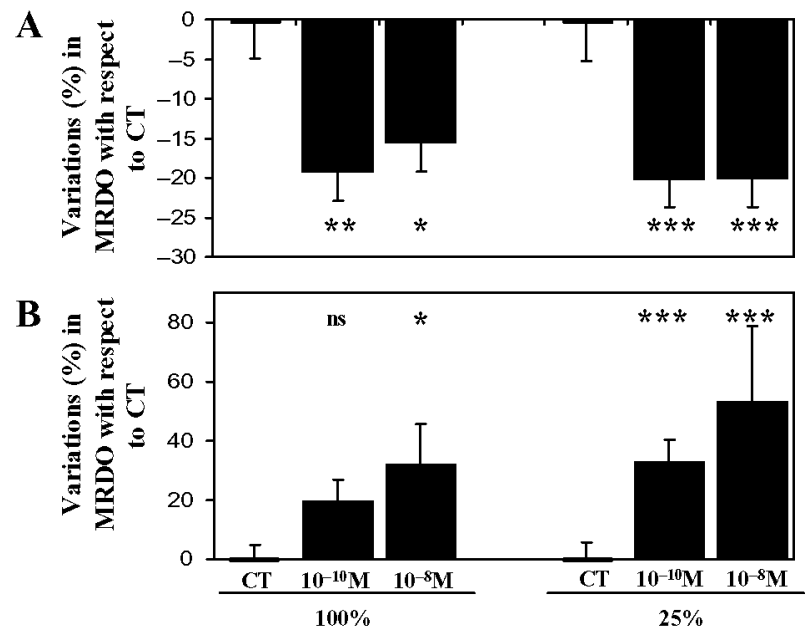

\section{Discussion}

Neurotensin is a tridecapeptide originally isolated from bovine hypothalamus and is located mainly in the CNS and the endocrinal cells ( $\mathrm{N}$ cells) of the jejunal and ileal mucosa [27]. It is synthesized in the neurones in the whole of the brain [35]. In the CNS, neurotensin plays the role of a neurotransmitter and also acts as a neuromodulator of dopamine transmission and anterior pituitary hormone secretion [26]. It also has potent hypothermic and analgesic effects in the brain [26]. However, as emphasized by Reubi [26], several lines of evidence also suggest that neurotensin plays a role in cancer. Several types of cancers, that is, small cell lung cancers, neuroblastomas, medulloblastomas, pancreatic cancers, colon cancers, meningiomas, Ewing's sarcomas, medullary thyroid carcinomas and astrocytomas, express NTRs [9,26]. As also argued by Reubi [26], an additional argument in favour of a role for neurotensin in cancer is the stimulation that this peptide exerts on the in vitro proliferation of tumour cell lines of various origins including the pancreas, the prostate and the lungs, and also of astrocytic tumour cell lines, as we have previously showed [10]. As is pointed out in the Introduction, the hallmark of malignant glioma development is their diffuse invasion of the brain parenchyma. This diffuse invasion is related to a myriad of individual tumour astrocytes migrating from the primary tumour site through the brain (possibly over long distances) [2]. Several studies have already pointed to a direct role played by neurotensin with respect to the migratory characteristics of a large set of cell types, including normal and tumour cells. For example, neurotensin modulates the locomotion of the neutrophils [37], the lymphocytes [38] and the macrophages [39] that form part of the immune system, and also of microglia in the CNS [40]. Neurotensin stimulates intestinal wound healing [41] and angiogenesis [42]. It also modulates the migration features of cancer cells such as circulating malignant Sezary cells [43]. The data from the present study clearly indicate that whereas neurotensin decreases the levels of motility of human U373 glioblastoma cells cultured on plastic in a serum-free medium, no such effects are observed in culture media supplemented with $5 \%$ foetal bovine serum (which may contain either some traces of neurotensin or a number of factors activating the same signalling pathways as neurotensin). Moreover, while the neurotensin-induced decrease in U373 cell motility on plastic in a serum-free medium was observed at 0.1 and $10 \mathrm{nM}$, this effect was abolished at a higher dose (1 $\mu \mathrm{M})$. We observed very similar effects on the Hs683 model (data not shown), another aggressive human glioma of oligodendroglial origins [23,24]. Most neuropeptides binding to GPCRs at physiological doses markedly modify the levels of expression and/or activity of a number of protein kinases C (PKCs) that play pivotal roles in the control of neuropeptide-mediated effects on cell proliferation and/or migration $[8,18]$. The lack of response to neuropeptides at pharmacological doses (in the micro-molar range) may be related to a desensitization process of the PKCs, as it has already been observed for gastrin in several cell systems $[5,8,44]$. Indeed, we observed higher gastrin-induced modifications at tumour astrocyte cell proliferation [5] and migration [8] levels at a concentration of $10 \mathrm{nM}$ rather than of $1 \mu \mathrm{M}$. A similar observation has been reported by Kimura et al. [44], who noted that whereas micromolar concentrations of gastrin-cholecystokinin-related peptides inhibit PKC activity in acini, physiological concentrations of these peptides activate PKC-dependent signals. 
Neurotensin signals its biological effects through NTR1, NTR2 and NTR3, the three different receptors identified to date which are widely expressed throughout the adult rat brain [29-31]. The NTR1 signalling pathway is well documented and includes $\mathrm{Ca}^{2+}$ release from inositol ${ }_{1,4,5}$-triphosphate $\left(\mathrm{IP}_{3}\right)$-sensitive channels, the activation of mitogen-activated protein Rinases (MAPKs) via PKC, and the activation of AP-1 [26,27]. In contrast, the signalling pathway that governs the interaction between neurotensin and NTR2 is a matter of controversy [26]. NTR2 seems to be involved in the analgesic effect of the peptide [26,40]. The activation of NTR3 by neurotensin leads to the phosphorylation of both extracellular signal-regulating kinases (ERK) $1 / 2$ MAPK and Akt [40]. In addition, Martin etal. [45] provide biochemical evidence for the heterodimerization of NTR1 and NTR3 in the human HT-29 colon cancer cell line. NTR3 is the only NTR present in all the cancer cells on which neurotensin has a proliferative effect [40]. It is the only known receptor expressed in human $\mathrm{C} 13 \mathrm{NJ}$ microglial cells, and the effect of neurotensin on the migration of these cells is preceded by a profound modification of the F-actin cytoskeleton, and particularly by the rapid formation of numerous cell filopodia [40], a feature also observed here in U373 glioblastoma cells treated with neurotensin. In the case of other cell types (such as T lymphocytes and leukaemic Jurkat cells) it seems that only NTR1 is responsible for cell migration [42]. The present study shows that human U373 glioblastoma cells express NTR1, NTR2 and NTR3 at least at mRNA level, an expression pattern that we also evidenced in Hs683 glioma cells (data not shown). We cannot argue at present in favour of one or another specific receptor as the mediator of the neurotensin-induced effects on U373 cells. We are now developing an siRNA approach targeting each of these three NTRs to further characterize which one(s) is (are) involved in the neurotensin-induced effects on U373 cell motility.

An intriguing finding of this study is the opposite effects of neurotensin on the motility of U373 cells cultured on plastic or laminin. These differences possibly reflect the engagement of different integrins depending of the culture support. With respect to this hypothesis, Ding et al. [46] reported that the physiological platelet-derived growth factor (PDGF) stimulation of U-87 MG glioblastoma cells largely promotes $\alpha \mathrm{v} \beta 3$-mediated motility on vitronectin in contrast to the much lower migration rates observed on collagen or laminin (which engage different integrins). On the other hand, the levels of eosinophil chemotaxis induced by the platelet-activating factor were enhanced on laminin but not on vitronectin [47]. These data illustrate the profound impact of the cell-matrix interactions through the engagement of different integrins on the regulation of cell migration by soluble factors.

The present study reveals that the neurotensin-induced effects observed in U373 cell motility are paralleled by profound modifications to the organization of the U373 actin cytoskeleton that could at least be partly explained by pronounced modifications at small GTPases activation level. Indeed, we observed that neurotensin is able to activate Racl and Cdc42 in U373 cells. These data agree with those reported by Zao et al. on human colonic epithelial cells overexpressing NTR1 [48]. The activation of Racl and Cdc42, which are known to stimulate the formation of actin-based membrane protrusions [19], might thus explain the morphological changes observed in the U373 cells treated with neurotensin. The accumulation of fibrillar actin to form strong adhesion plaques at the tips of the filopodial protrusions might also explain the restricted motility of U373 cells induced by neurotensin.

In conclusion, our data strongly suggest that neurotensin is a neuropeptide capable of modulating tumour astrocyte migration into the brain parenchyma by acting on the actin cytoskeleton and its regulators at least.

\section{Acknowledgement}

C. Deroanne is a research associate, C. Decaestecker is a senior research associate, and R. Kiss is a director of research with the 'fonds National de la Recherche Scientifique' (FNRS, Belgium). S. Servotte is the recipient of the 'Télévie' grant (FNRS).

\section{References}

1 Kleihues P, Cavenee WK (eds). Pathology and Genetics of Tumours of the Nervous System, World Health Organization Classification of Tumours. Lyon: IARC Press, 2000; 10-39

2 Lefranc F, Brotchi J, Kiss R. Possible future issues in the treatment of glioblastomas: special emphasis on cell migration and the resistance of migrating glioblastoma cells to apoptosis. J Clin Oncol 2005; 23: 2411-22

3 Rozengurt E. Neuropeptides as growth factors for normal and cancerous cells. Trends Endocrinol Metab 2002; 13: 128-33

4 Camby I, Salmon I, Danguy A, Pasteels JL, Brotchi J, Martinez J, Kiss R. Influence of gastrin on human astrocytic tumor cell proliferation. J Natl Cancer Inst 1996; 88: 594-600 
5 Lefranc F, Sadeghi N, Metens T, Brotchi J, Salmon I, Kiss R. Characterization of gastrin-induced cytostatic effect on cell proliferation in experimental malignant gliomas. Neurosurgery 2003; 52: 881-91

6 De Hauwer C, Camby I, Darro F, Migeotte I, Decae-stecker C, Verbeek C, Danguy A, Pasteels JL, Brotchi J, Salmon I, Van Ham P, Kiss R. Gastrin inhibits motility, decreases cell death levels and increases proliferation in human glioblastoma cell lines, J Neurobiol 1998; 37 : 3 73-82

7 Kucharczak J, Pannequin J, Camby I, Decaestecker C, Kiss R, Martinez J. Gastrin induces over-expression of genes involved in human U3 73 glioblastoma cell migration. Oncogene 2001; 20: 7021-8

8 Lefranc F, Camby I, Belot N, Bruyneel E, Chaboteaux C, Brotchi J, Mareel M, Salmon I, Kiss R. Gastrin significantly modifies the migratory abilities of experimental glioma cells. Lab Invest 2002; 82: 1241-52

9 Reubi JC, Waser B, Schaer JC, Laissue JA. Neurotensin receptors in human neoplasms: high incidence in Ewing sarcomas. Int J Cancer 1999; $82: 213-18$

10 Camby I, Salmon I, Bourdel E, Nagy N, Danguy A, Brotchi J, Pasteels JL, Martinez J, Kiss R. Neurotensin-mediated effects on astrocytic tumor cell proliferation. Neuropeptides 1996; 30: 133-9

11 Giese A, Rief MD, Loo MA, Berens ME. Determinants of human astrocytoma migration. Cancer Res 1994; 54: 389 7-904

12 Gladson CL. The extracellular matrix of gliomas: modulation of cell function, J Neuropathol Exp Neurol 1999 ; 58 : $1029-40$

13 Paulus W, Baur I, Huettner C, Schmausser B, Roggendorf W, Schlingensiepen KH, Brysch W. Effects of transforming growth factor- $\beta 1$ on collagen synthesis, integrin expression, adhesion and invasion of glioma cells. J Neuropathol Exp Neurol 1995; 54: 236-44

14 Chintala SK, Rao JS. Invasion of human glioma: role of extracellular matrix proteins. Front Biosci 1996; 1: 324-39

15 Haugland HK, Tysnes BB, Tysnes OB. Adhesion and migration of human glioma cells are differently dependent on extracellular matrix molecules. Anticancer Res 1997; 17: 1035-42

16 Raftopoulou M, Hall A. Cell migration: rho GTPases lead the way. Dev Biol 2004; 265: 23-32

17 Rozengurt E. Signal transduction pathways in the mito-genic response to G protein-coupled neuropeptide receptor agonists. $J$ Cell Physiol 1998; 177: 507-17

18 Rozengurt E, Walsh JH. Gastrin, CCK, signaling, and cancer. Annu Rev Physiol 2001; 63: 49-76

19 Hall A. Rho GTPases and the actin cytoskeleton. Science 1998;279:509-14

20 Nobes CD, Hall A. Rho, Rac and Cdc42 GTPases regulate the assembly of multimolecular focal complexes associated with actin stress fibers, lamellipodia, and filopodia. Cell 1995;81: 53-62

21 Ridley AJ, Hall A. The small GTP-binding protein rho regulates the assembly of focal adhesion and actin stress fibers in response to growth factors. Cell 1992; 70: 389-99

22 Ridley AJ, Paterson HF, Johnston CL, Diekmann D, Hall A. The small GTP-binding protein rac regulates growth factor-induced membrane ruffling. Cell 1992; 70: 401-10

23 Belot N, Rorive S, Doyen I, Lefranc F, Bruyneel E, DeDecker R, Micik S, Brotchi J, Decaestecker C, Salmon I, Kiss R, Camby C. The molecular characterization of cell-substratum attachments in human glial tumors relates to prognostic features. Glia 2001; 36: 3 75-90

24 Branle F, Lefranc F, Camby I, Jeuken J, Geurts-Moespot A, Sprenger S, Sweep F, Kiss R, Salmon I. Evaluation of the efficiency of chemotherapy in in vivo orthotopic models of human glioma cells with and without $1 \mathrm{p} 19 \mathrm{q}$ deletions and in C6 rat orthotopic allografts serving for the evaluation of surgery combined with chemotherapy. Cancer 2002;95:641-55

25 Rorive S, Belot N, Decaestecker C, Lefranc F, Gordower L, Micik S, Maurage CA, Kaltner H, Ruchoux MM, Danguy A, Gabius HJ, Salmon I, Kiss R, Camby I. Galectin-1 is highly expressed in human gliomas with relevance for modulation of invasion of tumor astrocytes into the brain parenchyma. Glia 2001; 33: 241-55

26 Reubi JC. Peptide receptors as molecular targets for cancer diagnosis and therapy. Endocr Rev 2003; 24: 389-427

27 Thomas RP, Hellmich MR, Townsend CM, Evers BM. Role of gastrointestinal hormones in the proliferation of normal and neoplastic tissues. Endocr Rev 2003; 24: 571-99

28 Vincent JP, Mazella J, Kitabgi P. Neurotensin and neurotensin receptors. Trends Pharmacol Sci 1999; 20: 302-9

29 Sarret P, Perron A, Stroh T, Beaudet A. Immunohis-tochemical distribution of NTS2 neurotensin receptors in the rat central nervous system, J Comp Neurol 2003; 461 : 520-38

30 Sarret P, Krzywkowski P, Segal L, Nielsen MS, Petersen CM, Mazella J, Stroh T, Beaudet A. Distribution of NTS3 receptor/sortilin mRNA and protein in the rat central nervous system, $J$ Comp Neurol 2003; 461: 483-505

31 Alexander MJ, Leeman SE. Widespread expression in adult rat forebrain of mRNA encoding high-affinity neurotensin receptor. $J$ Comp Neurol 1998; 402: 475-500

32 Ren XD, Kiosses WB, Schwartz MA. Regulation of the small GTP-binding protein Rho by cell adhesion and the cytoskeleton. EMBOJ 1999; $18: 578-85$

33 Sander EE, ten Klooster JP, van Delft S, van der Kammen RA, Collard JG. Rac downregulates Rho activity: reciprocal balance between both GTPases determines cellular morphology and migratory behavior. J Cell Biol 1999; 147: 1009-22

34 Debeir 0, Van Ham P, Kiss R, Decaestecker C. Tracking of migrating cells under phase-contrast video microscopy with combined meanshift processes. IEEE Trans Med Imaging 2005; 24: 69 7-711

35 Senger DL, Tudan C, Guiot MC, Mazzoni IE, Molenkamp G, LeBlanc R, Antel J, Olivier A, Snipes GJ, Kaplan DR. Suppression of Rac 
activity induces apoptosis of human glioma cells but not normal human astrocytes. Cancer Res 2002;62: 2131-40

36 Pettibone DJ, Hess JF, Hey PJ, Jacobson MA, Leviten M, Lis EV, Mallorga PJ, Pascarella DM, Snyder MA, Williams JB, Zeng Z. The effects of deleting the mouse neurotensin receptor NTR1 on central and peripheral responses to neurotensin, J Pharmacol Exp Ther 2002; 300:305-13

37 Goldman R, Bar-Shavit Z, Romeo D. Neurotensin modulates human neutrophil locomotion and phagocytic capability. FEBS Lett 1983; 159: $63-7$

38 Garrido JJ, Arahuetes RM, Hernanz A, De la Fuente M. Modulation by neurotensin and neuromedin N of adherence and chemotaxis capacity of murine lymphocytes. Regul Pept 1992; 41: 27-37

39 De la Fuente M, Garrido JJ, Arahuetes RM, Hernanz A. Stimulation of phagocytic function in mouse macrophages by neurotensin and neuromedin N. J Neuroimmunol 1993; 42: 97-104

40 Martin S, Vincent JP, Mazella J. Involvement of the neurotensin receptor-3 in the neurotensin-induced migration of human microglia. J Neuro science 2003; 23: 1198-205

41 Brun P, Mastrotto C, Beggiao E, Stefani A, Barzon L, Sturniolo GC, Palu G, Castagliuolo I. Neuropeptide neurotensin stimulates wound healing following chronic intestinal inflammation. Am J Physiol Gastrointest Liver Physiol 2005; 288: G621-9

42 Ushiro S, Mizoguchi K, Yoshida S, Jimi S, Fujiwara T, Yoshida M, Wei ET, Kitabgi P, Amagaya S, Ono M, Kuwano M. Stimulation of cell-surface urokinase-type plasminogen activator activity and cell migration in vascular endothelial cells by a novel hexapeptide analogue of neurotensin. FEBSLett 199 7; 418: 341-5

43 Magazin M, Poszepczynska-Guigne E, Bagot M, Boumsell L, Pruvost C, Chalon P, Culouscou JM, Ferrara P, Bensus-san A. Sezary syndrome cells unlike normal circulating T lymphocytes fail to migrate following engagement of NTR1 receptor. J Invest Dermatol 2004; 122: $111-18$

44 Kimura T, Honda T, Higashi T, Konishi J. High concentration of cholecystokinin octapeptide suppress protein kinase C activity in guinea pig pancreatic acini. Peptides 1996; 17: $917-25$

45 Martin S, Navarro V, Vincent JP, Mazella J. Neurotensin receptor-1 and -3 complex modulates the cellular signaling of neurotensin in the HT-29 cell line. Gastroenterology 2002;123: 1135-43

46 Ding 0, Stewart J Jr, Olman MA, Klobe MR, Gladson CL. The pattern of enhancement of Src kinase activity on platelet-derived growth factor stimulation of glioblastoma cells is affected by the integrin-engaged. J Biol Chem 2003;278: 39882-91

47 Yoshikawa M, Matsumoto K, Iida M, Akasawa A, Moriyama H, Saito H. Effect of extracellular matrix proteins on platelet-activating factor-induced eosinophil chemotaxis. Int Arch Allergy Immunol 2002; 128 (Suppl. 1):3-11

48 Zhao D, Kuhnt-Moore S, Zeng H, Wu JS, Moyer MP, Pothoulakis C. Neurotensin stimulates IL-8 expression in human colonic epithelial cells through Rho GTPase-mediated NF-kappa B pathways. Am J Physiol Cell Physiol 2003; 284: C1397-404 